\title{
Trimethoprim-Sulfamethoxazole for Treatment of Stenotrophomonas maltophilia Pneumonia in a Neonate
}

\author{
Karen Leask Ryan, Deonne Dersch-Mills, and Deborah Clark
}

\section{INTRODUCTION}

$\mathrm{N}$ eonates are susceptible to numerous infections. Factors that predispose these patients to nosocomial infections include very low birth weight, small size for gestational age, immunologic immaturity, and exposure to invasive procedures, including insertion of intravascular catheters and assisted ventilation. ${ }^{1,2}$ Stenotrophomonas maltophilia is an opportunistic, gram-negative aerobic bacillus with a high level of intrinsic resistance that is known to cause nosocomial infections. ${ }^{3-7}$ This organism may cause infections of many different systems, including bloodstream infections, urinary tract infections, meningitis, and (most commonly) pneumonia. ${ }^{3,6}$ Since neonatal patients are immunocompromised, infections with $S$. maltophilia are considered life-threatening in this population. ${ }^{2,8}$

There is very little evidence in the literature indicating the appropriate doses of trimethoprim-sulfamethoxazole required to treat $S$. maltophilia infections in neonates. This article describes a case in which trimethoprim-sulfamethoxazole was used to treat such an infection, with escalating doses used and tolerated.

\section{CASE REPORT}

An infant was born by spontaneous vaginal delivery at 24 weeks gestational age, with birth weight $650 \mathrm{~g}$ and APGAR scores of 5 and 7 at 1 and 5 min, respectively.* Rupture of the membranes had occurred 10 days before delivery, and the mother had been treated with oral amoxicillin and erythromycin for 9 days before delivery; she also received 2

\footnotetext{
* Since the infant described in this case report did not survive, consent was not requested out of sensitivity toward the parents. Potentially identifying demographic characteristics have been omitted from the report.
}

doses of betamethasone $\mathrm{q} 24 \mathrm{~h}$, started at the same time as the antibiotics, with a third dose given 2 days before delivery.

A plan was made to treat the infant empirically with ampicillin $50 \mathrm{mg} / \mathrm{kg}$ per dose IV q12h and gentamicin $5 \mathrm{mg} / \mathrm{kg}$ per dose IV q $48 \mathrm{~h}^{9}$ for 7 days (Table 1). Because of renal compromise noted on day 4 of life (creatinine $93 \mu \mathrm{mol} / \mathrm{L}$ ), the gentamicin was discontinued, and cefotaxime $50 \mathrm{mg} / \mathrm{kg}$ per dose IV q12h was instituted. On day 7 of life, reddening of the umbilicus was noted, and a partial septic work-up was performed. At that time, the cefotaxime was continued and the ampicillin was changed to vancomycin $15 \mathrm{mg} / \mathrm{kg}$ per dose IV q24h. Complete blood count on day 7 of life showed elevation of total leukocytes $\left(23.1 \times 10^{9} / \mathrm{L}\right)$ and neutrophils $(17.1 \times$ $10 \% / \mathrm{L})$; antibiotic therapy was therefore continued for 7 more days, for a total duration of 14 days. However, on the day after completion of this antibiotic regimen, the infant appeared hypotonic and lethargic, with increased ventilation requirements and radiographic changes visible in both lungs. Meropenem $20 \mathrm{mg} / \mathrm{kg}$ per dose IV q12h was started as treatment for a possible respiratory infection. Culture of endotracheal aspirate obtained the following day (day 15 of life) revealed gram-negative bacilli. Three days later, the organism was determined to be $S$. maltophilia. A blood sample, obtained after the endotracheal culture grew $S$. maltophilia, was sterile.

The S. maltophilia growing in the endotracheal tube showed sensitivity to ticarcillin-clavulanate, colistimethate, levofloxacin, and trimethoprim-sulfamethoxazole and resistance to meropenem. Trimethoprim-sulfamethoxazole was chosen for the following reasons: ticarcillin-clavulanate was considered to be less active in vivo than trimethoprim-sulfamethoxazole, colistimethate has shown more nephrotoxicity than trimethoprim-sulfamethoxazole, and the only data for fluoroquinolone use against $S$. maltophilia were from case reports using ciprofloxacin. ${ }^{5,7,8}$ 
Table 1. Antibiotic Use over Patient's Lifetime

\begin{tabular}{|c|c|c|c|c|}
\hline Day of Life & Antibiotic and Dose* & Positive Culture Results & $\begin{array}{c}\text { Serum Creatinine } \\
(\mu \mathrm{mol} / \mathrm{L})\end{array}$ & $\begin{array}{l}\text { Bilirubin } \\
(\mu \mathrm{mol} / \mathrm{L})\end{array}$ \\
\hline$\overline{0-4}$ & $\begin{array}{l}\text { Ampicillin } 50 \text { mg/kg IV q12h } \\
\text { Gentamicin } 5 \text { mg/kg IV q48h }\end{array}$ & & 93 (DOL 4) & \\
\hline $5-6$ & $\begin{array}{l}\text { Ampicillin } 50 \mathrm{mg} / \mathrm{kg} \text { IV q12h } \\
\text { Cefotaxime } 50 \mathrm{mg} / \mathrm{kg} \text { IV q12h }\end{array}$ & & $\begin{array}{l}87 \text { (DOL 5) } \\
78 \text { (DOL 6) }\end{array}$ & \\
\hline$\overline{7-11}$ & $\begin{array}{l}\text { Cefotaxime } 50 \mathrm{mg} / \mathrm{kg} \text { IV q12h } \\
\text { Vancomycin } 15 \mathrm{mg} / \mathrm{kg} \text { IV q24h }\end{array}$ & & & \\
\hline $12-13$ & Vancomycin 15 mg/kg IV q24h & & 113 (DOL 13) & \\
\hline$\overline{14-17}$ & Meropenem 20 mg/kg IV q12h & $\begin{array}{l}\text { Gram-negative bacilli } \\
\text { (endotracheal aspirate, DOL 15) }\end{array}$ & $\begin{array}{l}107 \text { (DOL14) } \\
88 \text { (DOL 17) }\end{array}$ & \\
\hline$\overline{18}$ & $\begin{array}{l}\text { Trimethoprim-sulfamethoxazole } \\
3 \mathrm{mg} / \mathrm{kg} \text { IV load }\end{array}$ & $\begin{array}{l}\text { Stenotrophomonas maltophilia } \\
\text { (endotracheal aspirate) }\end{array}$ & 121 & \\
\hline 19-25 & $\begin{array}{l}\text { Trimethoprim-sulfamethoxazole } \\
1 \mathrm{mg} / \mathrm{kg} \text { IV q12h }\end{array}$ & $\begin{array}{l}\text { Stenotrophomonas maltophilia } \\
\text { (endotracheal aspirate, } \\
\text { DOL } 20,22,24 \text { ) }\end{array}$ & $\begin{array}{c}89 \text { (DOL 19) } \\
105 \text { (DOL 20, } \\
21,23) \\
122 \text { (DOL 25) }\end{array}$ & $\begin{array}{l}23 \text { (DOL 19) } \\
3 \text { (DOL 23) }\end{array}$ \\
\hline $26-29$ & $\begin{array}{l}\text { Trimethoprim-sulfamethoxazole } \\
1 \mathrm{mg} / \mathrm{kg} \text { IV q12h } \\
\text { Levofloxacin } 10 \mathrm{mg} / \mathrm{kg} \text { PO q12h }\end{array}$ & $\begin{array}{l}\text { Stenotrophomonas maltophilia } \\
\text { (endotracheal aspirate, } \\
\text { DOL 26, 29) }\end{array}$ & 87 (DOL 26) & 15 (DOL 26) \\
\hline 30 & $\begin{array}{l}\text { Trimethoprim-sulfamethoxazole } \\
2 \mathrm{mg} / \mathrm{kg} \text { IV q6h } \\
\text { Levofloxacin } 10 \mathrm{mg} / \mathrm{kg} \text { PO q12h }\end{array}$ & & & \\
\hline $31-32$ & $\begin{array}{l}\text { Trimethoprim-sulfamethoxazole } \\
2 \mathrm{mg} / \mathrm{kg} \text { PO q6h } \\
\text { Levofloxacin } 10 \mathrm{mg} / \mathrm{kg} \text { PO q12h }\end{array}$ & $\begin{array}{l}\text { Stenotrophomonas maltophilia } \\
\text { (endotracheal aspirate, } \\
\text { DOL 31, 32) }\end{array}$ & 84 (DOL 31) & $11(\mathrm{DOL} 31)$ \\
\hline 33-39 & $\begin{array}{l}\text { Trimethoprim-sulfamethoxazole } \\
2.5 \mathrm{mg} / \mathrm{kg} \text { PO q6h } \\
\text { Levofloxacin } 10 \mathrm{mg} / \mathrm{kg} \text { PO q12h }\end{array}$ & $\begin{array}{l}\text { Stenotrophomonas maltophilia } \\
\text { (endotracheal aspirate, } \\
\text { DOL } 34,38 \text { ) }\end{array}$ & $\begin{array}{l}60 \text { (DOL 33) } \\
39 \text { (DOL 38) }\end{array}$ & \\
\hline$\overline{40}$ & $\begin{array}{l}\text { Trimethoprim-sulfamethoxazole } \\
5 \mathrm{mg} / \mathrm{kg} \text { PO q6h } \\
\text { Levofloxacin } 10 \mathrm{mg} / \mathrm{kg} \text { PO q12h }\end{array}$ & & & 8 \\
\hline$\overline{41-42}$ & $\begin{array}{l}\text { Trimethoprim-sulfamethoxazole } \\
5 \mathrm{mg} / \mathrm{kg} \text { IV q6h } \\
\text { Levofloxacin } 10 \mathrm{mg} / \mathrm{kg} \mathrm{IV} \mathrm{q12h} \\
\text { Vancomycin } 15 \mathrm{mg} / \mathrm{kg} \text { IV q24h } \\
\text { Cefotaxime } 50 \mathrm{mg} / \mathrm{kg} \text { IV q6h }\end{array}$ & & 43 (DOL 41) & \\
\hline
\end{tabular}

$\overline{\mathrm{DOL}}=$ day of life when sample was collected for culture or other testing.

*Trimethoprim-sulfamethoxazole doses refer to trimethoprim component.

No literature is available to guide the dose of trimethoprim-sulfamethoxazole to be prescribed for neonates with S. maltophilia infection, although there have been case reports describing the use of this medication for other types of infections in neonates. ${ }^{10}$ Therefore, the Pediatric Infectious Disease Service was consulted, and the following regimen was chosen, based on a pharmacokinetic study ${ }^{11}$ : loading dose of $3 \mathrm{mg} / \mathrm{kg}$ trimethoprim component IV, followed by $1 \mathrm{mg} / \mathrm{kg}$ per dose trimethoprim component IV q12h. The expectation was to continue trimethoprim-sulfamethoxazole until 10 days after the first negative result on culture of endotracheal aspirate.

After the first dose of trimethoprim-sulfamethoxazole, the infant's urine output declined to $0.2 \mathrm{~mL} / \mathrm{kg}$ per hour for $8 \mathrm{~h}$. This change was not considered to be due to the medication, as trimethoprim-sulfamethoxazole would be unlikely to reduce renal function so quickly and the infant had previously experienced variance in renal function. No other antibiotic was added at this time.

After 8 days of trimethoprim-sulfamethoxazole therapy, levofloxacin $10 \mathrm{mg} / \mathrm{kg}$ per dose $\mathrm{PO} \mathrm{q} 12 \mathrm{~h}$ was added because of case reports of fluoroquinolones having activity against $S$. maltophilia ${ }^{5,8}$; this antibiotic was continued for the duration of treatment. After 13 days of treatment with trimethoprimsulfamethoxazole, and 5 days of combination therapy with levofloxacin, S. maltophilia continued to grow in the sputum. Clinically, the infant's oxygen requirements had continued to increase. The infant's condition was otherwise stable, with toleration of enteral feeding, which was why the levofloxacin (bioavailability $99 \%{ }^{12}$ ) was given enterally. The Pediatric Infectious Disease Service reviewed the case again and suggested 
that the dose of trimethoprim-sulfamethoxazole be increased to $3.75-5 \mathrm{mg} / \mathrm{kg}$ per dose trimethoprim component IV q6h. This dose was to be adjusted for renal function, as the infant's recent serum creatinine had been as high as $122 \mu \mathrm{mol} / \mathrm{L}$, with periodic decrease in urine output. The Nephrology Service recommended trimethoprim-sulfamethoxazole $2.5 \mathrm{mg} / \mathrm{kg}$ per dose trimethoprim component IV q6h. The Neonatology team chose to be more conservative with dosing of this antibiotic and decided on a dose of $2 \mathrm{mg} / \mathrm{kg}$ per dose trimethoprim component IV q6h, starting on day 30 of life. The infant tolerated the increased dose for $12 \mathrm{~h}$, at which point the route was changed from IV to oral at the same dose.

The infant's clinical condition continued to deteriorate, with worsening respiratory disease and little change evident in serial chest radiographs. As the infant's condition worsened, the dose of trimethoprim was progressively increased to a maximum of $5 \mathrm{mg} / \mathrm{kg}$ per dose trimethoprim component q6h (Table 1). Inhaled colistimethate was considered but was not prescribed.

On day 42 of life, after 26 days of trimethoprimsulfamethoxazole treatment, the infant died because of the infection. In the final week of life, the infant had significant hypoxic and hypercapneic respiratory failure resistant to various modes of ventilation and to broad-spectrum antibiotics, surfactant, high-dose hydrocortisone, and dexamethasone. Common causes of neonatal morbidity and mortality, such as intracranial hemorrhage and patent ductus arteriosus, were not evident from diagnostic imaging performed throughout the infant's life.

\section{DISCUSSION}

A literature search for information on trimethoprimsulfamethoxazole pharmacokinetics in neonates yielded only one small pharmacokinetic study. ${ }^{11}$ It reported the serum half-life in neonates as much longer than that observed in adults, with half-lives of $24.6 \mathrm{~h}$ and $23.3 \mathrm{~h}$ after repeated doses for the trimethoprim and sulfamethoxazole components, respectively, compared with half-life in adults of 6 to $11 \mathrm{~h}^{.13} \mathrm{In}$ the case reported here, the dosage found to achieve therapeutic concentrations was a loading dose of $3 \mathrm{mg} / \mathrm{kg}$ trimethoprim component followed by a maintenance dose of $1 \mathrm{mg} / \mathrm{kg}$ trimethoprim component, given $\mathrm{q} 12 \mathrm{~h}$. This dosage was determined by inserting the desired therapeutic level into an equation that uses the half-life as determined in the pharmacokinetic study. ${ }^{11}$ It should be noted that the pharmacokinetic study described treatment of an outbreak of highly resistant Klebsiella pneumoniae ${ }^{11}$ and so may not be directly applicable to treatment of Stenotrophomonas. In the case reported here, the infection persisted after this dosage was instituted; hence, it may not be sufficient for resistant opportunistic pathogens such as $S$. maltophilia.
The dose of trimethoprim-sulfamethoxazole eventually recommended by the Pediatric Infectious Disease Service (3.75-5 $\mathrm{mg} / \mathrm{kg}$ per dose trimethoprim component IV divided $\mathrm{q} 6 \mathrm{~h})$ is the dose recommended for serious infections such as Pneumocystis in children older than 2 months of age. ${ }^{14} \mathrm{~A}$ high dose of trimethoprim-sulfamethoxazole may be required to treat antibiotic-resistant infections, such as S. maltophilia, in neonates, because of increased volume of distribution. ${ }^{13}$ The pharmacokinetic study showed volumes of distribution of $2.7 \mathrm{~L} / \mathrm{kg}$ and $0.48 \mathrm{~L} / \mathrm{kg}$ for the trimethoprim and sulfamethoxazole components, respectively.1 ${ }^{11}$ These volumes of distribution are greater than those found in adults, where values of $1.0 \mathrm{~L} / \mathrm{kg}$ and $0.2 \mathrm{~L} / \mathrm{kg}$ have been reported for the trimethoprim and sulfamethoxazole components, respectively. ${ }^{15}$ In neonates, extracellular fluid accounts for up to $40 \%$ of total body water, more than that found in infants at 1 year of age $(25 \%)$ and twice that of adults (20\%). As such, a higher dose is required to achieve therapeutic drug concentrations of trimethoprim-sulfamethoxazole.

Generally, trimethoprim-sulfamethoxazole is not prescribed for newborns because the sulfamethoxazole component increases the risk of hyperbilirubinemia and kernicterus. ${ }^{16,17}$ Although the risks for the patient described here were known, trimethoprim-sulfamethoxazole was chosen on the basis of best evidence for treating infections caused by $S$. maltophilia. Bilirubin monitoring, performed every few days throughout the treatment period, showed a decrease in bilirubin over time and, consequently, no risk of kernicterus. The infant experienced no other symptoms that were attributed to side effects of trimethoprim-sulfamethoxazole.

The infant described in this case had no evidence of the common causes of neonatal morbidity and mortality, such as intracranial hemorrhage or patent ductus arteriosus. The infant did experience periods of renal insufficiency, but these were considered to have been due to causes other than the use of trimethoprim-sulfamethoxazole, as renal function had varied before initiation of this antibiotic. Some of the risk factors for acquiring $S$. maltophilia infection in this case included immunocompromise, low birth weight, exposure to an endotracheal tube, and mechanical ventilation, as well as treatment with multiple antibiotics.

\section{CONCLUSIONS}

This case emphasizes the need to start antibiotic therapy in neonates at appropriate dosages and highlights the need for studies on neonatal dosing of antibiotics. To our knowledge, there are no reports for trimethoprim-sulfamethoxazole dosages as high as those used in this case; as such, more study of the use of trimethoprim-sulfamethoxazole in this population is required. 


\section{References}

1. Bartels DB, Schwab F, Geffers C, Poets CF, Gastmeier P. Nosocomial infection in small for gestational age newborns with birth weight <1500g: a multicentre analysis. Arch Dis Child Fetal Neonatal Ed. 2007;92(6):F449-53.

2. Moro ML, De Toni A, Stolfi I, Carrieri MP, Braga M, Zunin C. Risk factors for nosocomial sepsis in newborn intensive and intermediate care units. Eur J Pediatr. 1996;155(4):315-22.

3. Stenotrophomonas maltophilia. In: Tabers cyclopedic medical dictionary. 21 st ed. Charlottesville (VA): Unbound Medicine Inc; [cited 2012 Dec 18]. Available from: http://online.statref.com/document.aspx?fxid=57\&docid= 58026. Subscription required to access content.

4. Mutlu M, Yilmas G, Aslan Y, Bayramoglu G. Risk factors and clinical characteristics of Stenotrophomonas maltophilia infections in neonates. $J$ Microbiol Immunol Infect. 2011;44(6):467-72.

5. Gulcan H, Kuzucu C, Durmaz R. Nosocomial Stenotrophomonas maltophilia cross-infection: three cases in newborns. Am J Infect Control. 2004;32(6):365-8

6. Kagen J, Zaoutis TE, McGowan KL, Luan X, Shah SS. Bloodstream infection caused by Stenotrophomonas maltophilia in children. Pediatr Infect Dis J. 2007;26(6):508-12.

7. Abbassi MS, Touati A, Achour W, Cherif A, Jabnoun S, Khrouf N, et al. Stenotrophomonas maltophilia responsible for respiratory infections in neonatal intensive care unit: antibiotic susceptibility and molecular typing. Pathol Biol (Paris). 2009;57(5):363-7.

8. Lo WT, Wang CC, Lee CM, Chu ML. Successful treatment of multi-resistant Stenotrophomonas maltophilia meningitis with ciprofloxacin in a pre-term infant. Eur J Pediatr. 2002;161(12):680-2.

9. Dersch-Mills D, Akierman A, Alshaikh B, Yusuf K. Validation of a dosage individualization table for extended-interval gentamicin in neonates. Ann Pharmacother. 2012;46(7-8):935-42.

10. Sakuma H, Suzuki T. Successful treatment of neonatal meningitis caused by Chryseobacterium meningosepticum with intravenous ciprofloxacin and trimethoprim-sulfamethoxazole. Infect Dis Clin Pract. 2008;16(2):137-8.

11. Springer C, Eyal F, Michel J. Pharmacology of trimethoprim-sulfamethoxazole in newborn infants. J Pediatr. 1982;100(4):647-50.

12. Levofloxacin. In: Lexi-Comp online: pediatric Lexi-drugs online. Hudson $(\mathrm{OH})$ : Lexicomp; [cited 2013 Jul 12]. Available from: http://online.lexi.com/ lco/action/doc/retrieve/docid/pdh_f/2850780. Subscription required to access content.
13. Routledge P. Pharmacokinetics in children. J Antimicrob Chemother. 1994;34 Suppl A:19-24.

14. Sulfamethoxazole and trimethoprim. In: Lexi-Comp online: pediatric Lexi-drugs online. Hudson (OH): Lexicomp; [cited 2012 Apr 5]. Available from: http://online.lexi.com/lco/action/doc/retrieve/docid/pdh_f/129618. Subscription required to access content.

15. Drug detail for adult drugs: trimethoprim. In: Dosing guidelines for adults. Louisville (KY): University of Louisville, Kidney Disease Program; [cited 2013 Aug 1]. Available from: http://kdpnet.louisville.edu/renalbook/adult/id/174/

16. Hale T. Medications in mothers' milk [website]. Amarillo (TX): Hale Publishing; [cited 2012 Nov 14]. Available from: www.medsmilk.com/ drugs/view/2402. Registration required to access content.

17. Schwartz HP, Haberman BE, Ruddy RM. Hyperbilirubinemia: current guidelines and emerging therapies. Pediatr Emerg Care. 2011;27(9):884-9.

Karen Leask Ryan, BSP, ACPR, is with Alberta Children's Hospital, Alberta Health Services, Calgary, Alberta.

Deonne Dersch-Mills, BSCPharm, ACPR, PharmD, is with Alberta Health Services, Calgary, Alberta.

Deborah Clark, MB, CHB, is with Alberta Health Services, Calgary, Alberta.

Competing interests: None declared

Address correspondence to:

Karen Leask Ryan

Alberta Children's Hospital

Alberta Health Services

2888 Shaganappi Trail NW

Calgary AB T3B 6A8

e-mail: Karen.Ryan@albertahealthservices.ca

\begin{tabular}{|c|c|c|}
\hline & Ad Page & Prescribing Information \\
\hline Alberta Health Services & 342 & - \\
\hline Astellas / Xtandi & 340,341 & 398 \\
\hline CATIE / Corporate & 383 & - \\
\hline Pfizer / Injectables & IFC & - \\
\hline Pfizer / Injectables & 338 & - \\
\hline Pharmaceutical Partners of Canada / Corporate & OBC & - \\
\hline
\end{tabular}

